\title{
Predicting Rheological Properties of Wheat Dough Based on Wheat Characteristics
}

\author{
B. Wade Brorsen (Corresponding author) \\ Department of Agricultural Economics, Oklahoma State University, Stillwater, OK 74078, USA \\ Tel: 1-405-744-6836 E-mail: wade.brorsen@okstate.edu \\ Patricia Rayas-Duarte \\ Robert M. Kerr Food \& Agricultural Products Center \\ Department of Biochemistry and Molecular Biology, Stillwater OK 74078, USA \\ E-mail: pat.rayas_duarte@okstate.edu \\ Dasheng Ji \\ Fifth Third Bank, 38 Fountain Sq Plz, Cincinnati, OH 45263, USA \\ E-mail: jdasheng@hotmail.com
}

Received: July 14, 2011

Accepted: August 10, $2011 \quad$ Online Published: December 29, 2011

doi:10.5539/jas.v4n3p79

URL: http://dx.doi.org/10.5539/jas.v4n3p79

This research was supported by the Oklahoma Agricultural Experiment Station.

\begin{abstract}
The objective of this study is to find the relationship between rheological properties of wheat dough and some easily measured kernel properties. Hard red winter wheat samples (449) from crop years 1998-2001 were collected at grain elevators throughout the state of Oklahoma in the United States of America. The effects of single kernel characterization, test weight, and kernel protein content on dough Farinograph properties are estimated using both a four-year pooled model and single-year models. Across the Farinograph variables (absorption, peak time, and stability), the most reliable measures for predicting the dough properties were wheat protein and kernel hardness. Test weight was often significant, but test weight had reduced absorption in 1998 and increased absorption in other years. Kernel hardness is a measure that could be added to the current industry use of test weight and protein.
\end{abstract}

Keywords: Dough mixing properties, Dough quality, Farinograph, Protein, Wheat kernel characteristics

\section{Introduction}

Knowing the likely dough quality of wheat before it is purchased is of great value to millers. By knowing the dough quality, millers can avoid purchasing grain that does not meet their needs or can adjust the milling and blending process for given wheat properties. The milling and baking quality of wheat dough is commonly measured by its rheological properties such as viscosity, elasticity, and extensibility (Hrušková and Šmejd 2003). The Farinograph and the Alveograph are two of the most popular instruments used to measure rheological properties (Miralbés, 2004) such as water absorption to form dough of specified consistency, tolerance of flour to mixing, and dough strength and extensibility. The drawback of these two measurement methods is that they are time consuming and costly. Both are impractical to use as a way to either pay producers premiums based on flour quality or to sort each truckload based on flour quality. A number of measures of wheat kernel quality, however, can be conducted relatively less expensively and quickly. The question then is how helpful are these wheat kernel quality measures in predicting dough quality. Xu et al. (2001) study the effect of wheat proteins, especially gluten, on the mechanism controlling flow and deformation in the dough. Several other studies evaluate the performance of aggregate kernel-level measurements for predicting wheat qualities such as flour yield (Osborne, et al., 1997; Yoon et al., 2002; Lyford et al. 2005), and baking and milling quality (Gaines et al., 1997; Ohm et al., 1998). However, there are only a few studies on using wheat characteristics to predict the reheological properties of wheat dough (Osborne et al., 2007; Anderssen and Haraszi 2009; Baker et al 1999). 
This area needs more research. As research on the mechanical properties of wheat kernels and their possible relations to composition and functionality continue to expand (Figueroa et al., 2011a, 2011b), the opportunity to develop new approaches to predict dough properties based on kernel characteristics will continue to be explored.

The objective of this study is to find the relationship between the rheological properties of wheat dough as measured by the Farinograph and some easily measured wheat kernel properties. The single kernel characterization system (SKCS) measures a variety of kernel-level physical characteristics such as kernel hardness, weight, and diameter (Martins et al., 1993, Osborne et al., 2001). We focus on these three SKCS measures due to them being more widely used than the other SKCS measures. We also use two other easily measured wheat properties, wheat kernel protein and test weight. The relationship is estimated using a large data set with samples from four crop years. Of additional interest is how much the relationship changes across crop years.

\section{Materials and Methods}

\subsection{Wheat samples}

Hard red winter wheat samples from the crop years 1998, 1999, 2000, and 2001 were collected at several grain elevators throughout the state of Oklahoma in the United States. In 1998 and 1999, only truckloads were sampled. In 2000 and 2001, half of the samples were from truckloads and half from elevators. In total, 449 grain samples were collected and analyzed.

\subsection{Kernel analysis}

Test weight is the only independent variable that is included in United States wheat grades. Wheat test weight was analyzed using Approved Method 55-10.01 (AACCI, 2000). Single kernel characterization was measured with Approved Method 55-31.01 (AACCI, 2000). The wheat non-grade data are wheat protein and single kernel data of kernel hardness and kernel diameter as well as the standard deviations of the two kernel data variables. Protein and moisture contents of wheat and flour were analyzed by near infrared reflectance using an Inframatic 9140 (Perten Instruments, Huddinge, Sweden) following the manufacturer's protocol. Wheat was milled into flour using Approved Method 26-50 (AACCI, 2000) in a Brabender Quadrumat Jr. mill (C.W. Brabender Instruments, Inc., South Hackensack, NJ).

\subsection{Physical (rheological) properties of dough}

Flours were analyzed for dough peak (development) time, stability time, and optimum water absorption (adjusted to $14 \%$ protein content) at $63 \mathrm{rpm}$ and $30^{\circ} \mathrm{C}$ in a $300 \mathrm{~g}$ bowl Farinograph (C.W. Brabender Instruments, Hackensack, NJ) according to Approved Method 54-21.01 (AACCI 2000). The descriptive statistics of these variables are reported in Table 1.

\subsection{Mixed models with fixed and random effects}

The basic idea of the regression analysis is that each of the three dough property variables is a function of the independent variables. The regression assumes that there is a relationship between the dough property variables and the independent variables. However, the observed relationship between the dough property and the independent variables can be affected by other factors (i.e., environmental) that vary by year, but could not be measured. To correctly describe the mixed relationship between the variables, we need a mixed model that takes both the fixed and random effects into account. The mixed model generalizes the standard linear model as:

$$
y_{t i}=\alpha+\sum_{j} \beta_{j} X_{j t i}+\gamma_{t}+\varepsilon_{t i}
$$

where the subscript $t$ represents year, the $i$ is the observation number, and the $j$ indicates the independent variable that $X$ represents, $y$ represents a dough property as measured by the Farinograph. $X$ s represent the data of test weight, wheat protein, kernel hardness, hardness standard deviation, kernel diameter, and diameter standard deviation. $\beta \mathrm{s}$ are unknown constant coefficients. $\gamma_{t} \mathrm{~s}$ are unknown random-effects parameters. $\varepsilon$ and $\gamma$ are Gaussian random variables that are uncorrelated and have expectations 0 and constant variances $\sigma^{2}$ and $v^{2}$ respectively. The conditional variance of $y$ is therefore, $\sigma^{2}+v^{2}$. Both a four-year pooled model and four single-year models are estimated. For the four-year pooled model, restricted maximum likelihood was used to estimate the parameters due to the inclusion of the year random effect. For the single-year models, ordinary least squares were used.

\subsection{Elasticity index}

In addition to statistical significance, a measure of the size of the effects is needed. Regression coefficients can be difficult to compare because they are in different units. We use an elasticity (not the same as dough elasticity), which is a unitless measure, to show the functional effects of the independent variables on the dough properties: 


$$
\text { Elasticity }=\frac{\Delta Y}{\Delta X} / \overline{\bar{Y}}
$$

where $Y$ is a dependent variable, $X$ is the independent variable, $\Delta$ denotes the change in a variable, $\bar{X}$ and $\bar{Y}$ represent the mean values of the two variables. Elasticity measures the relative percentage change of the two variables. In a linear model, $\Delta Y / \Delta X$ is the coefficient of the independent variable.

\subsection{Statistical analysis}

The procedure PROC MIXED in SAS was used to estimate the four-year pooled model for each of the three dough quality variables (SAS statistical analysis package version 9.2, SAS Institute, Cary, North Carolina, USA). The likelihood ratio test is used to indicate the significance of the mixed model over the null model with no random effects. To estimate the four single-year models, the procedure PROC REG in SAS was used.

\section{Results and Discussion}

The estimated four-year pooled model is reported in Table 2. The variables that show statistically significant fixed effects on the dough properties are roughly the same in each of the Farinograph models. Across the Farinograph variables, the consistently significant variables are wheat protein and kernel hardness. Test weight is significant in the models of peak time and stability, but not in the model of water absorption. Hardness standard deviation is significant in the model of water absorption, but not in the other two models. Also, kernel diameter is significant in peak time, but not in the others. The patterns of the random effects are different for the dough property variables. The random effect variances are less than $10 \%$ of the error variances for water absorption and peak time. The random effect variance for stability, however, is more than $20 \%$ of the error variance, which indicates greater year-to-year variability that is unexplained by the model. The likelihood ratio tests clearly reject the null hypothesis of no random effects.

The estimation results for the four single-year models are reported in Table 3. With the single-year models, statistical significance of the fixed effects is largely reduced and the direction of the effect sometimes varies by year. For example, test weight has a significant effect on water absorption in 1998, 1999 and 2001, but not in 2000. The coefficient of test weight for absorption in 1998 is negative and significant, but positive and also significant in 1999 and 2001. For water absorption, the wheat protein has a significant positive effect in all four years. The coefficients of wheat protein are similar across years with values of 1.95, 1.98, 1.22 and 1.66. The kernel hardness has a significant positive effect in 1999, 2000, and 2001. The magnitudes of the effect in the three years are close at $0.05,0.05$, and 0.08 , which is encouraging that the effects are so similar. There is no consistent significance pattern available for the single-year models of peak time. For 1998, no wheat characteristic has a significant effect on peak time. For stability, test weight and wheat protein have a significant effect in 1998 and 1999, but not in 2000 and 2001. The magnitudes of the effects in the two years are -0.49 and -0.55 for test weight and -1.27 and -1.17 for wheat protein. For each of the four years, the R-squared for the water absorption model is higher than the R-squareds for the other two models, which indicates that water absorption can be predicted more accurately than stability or peak time. Except in 1998, the R-squared for the peak time model is higher than the one for stability. The highest R-squared for peak time is 0.44 in 2000 , which indicates there is still considerable variation that is unexplained by the model.

Osborne et al. (2007) also found kernel hardness was correlated with dough quality. Baker et al. (1999) found that protein was not a consistent predictor of dough quality. Even though we found that the effect of protein was stable over time, the results of Baker et al. suggest that may not always be true.

The elasticities (percentage changes in the dependent variables with percentage changes in the independent variables) between the wheat property and flour quality for the four years are reported in Table 4. For example, the elasticity of -0.27 for test weight and absorption means that a $1 \%$ increase in test weight would result in a $0.27 \%$ decrease in absorption. Test weight, wheat protein, and kernel hardness show the largest effects as measured by the elasticities. The highest elasticity is 4.15 for wheat protein and peak time in 2000. Elasticities are generally smaller for absorption than the other dough quality measures, but this is only due to absorption having a small standard deviation relative to its mean.

\section{Conclusions and Recommendations}

The relationships between the dough properties and wheat kernel properties are investigated. The results show some predictability of the wheat kernel properties for the dough properties, with absorption being the property that is most accurately predicted. By using the data of the hard red winter wheat during the four crop years in Oklahoma, it is found that the most reliable measures for predicting the dough properties are the wheat protein and kernel hardness. Test weight, hardness standard deviation and kernel diameter show some prediction power 
for some dough properties. Test weight is the only measure considered that is a factor in the United States Department of Agriculture wheat grading system. Test weight and protein are commonly used measures in the wheat trade. The results here suggest that hardness is an additional measure that could be helpful in predicting dough quality. Kernel hardness could be a good candidate to consider as a measure of quality for wheat purchasers or as an addition to the wheat grading system.

\section{References}

AACCI. (2000). AACC International Approved Methods, 11th Ed. Method 54-21.01. Farinograph Method for Flour. doi: 10.1094/AACCIntMethod-54-21.01. Method 26-50.01 Experimental Milling, Brabender Quadrumat Jr. (Quadruplex) Method. doi:10.1094/AACCIntMethod-26-50.01. Method 55-10.01Test Weight per Bushel. doi: 10.1094/AACCIntMethod-55-10.01. Method 55-31.01 Single-Kernel Characterization System for Wheat Kernel Texture. doi: 10.1094/AACCIntMethod-55-31.01. AACC International, St. Paul, MN, USA.

Anderssen, R. S., \& Haraszi, R. (2009). Characterizing and exploiting the rheology of wheat hardness. European Food Research and Technology, 229(1), 159-174. http://www.springerlink.com/content/n5033w154rn00m0q/

Baker, S., Herrman, T. J., \& Loughin, T. (1999). Segregating hard red winter wheat into dough factor groups using single kernel measurements and whole grain protein analysis1. Cereal Chemistry, 76(6), 884-889. http://dx.doi.org/10.1094/CCHEM.1999.76.6.884

Figueroa, J. D. C., Hernández, Z. J. E., Véles, M. J. J., Rayas-Duarte, P., Martínez-Flores, H. E., \& Ponce-García, N. (2011a). Evaluation of degree of elasticity and other mechanical properties of wheat kernels. Cereal Chemistry. 88(1), 12-18. http://dx.doi.org/10.1094/CCHEM-04-10-0065.

Figueroa, J. D. C., Peña, R. J., Maucher, T., Rayas-Duarte, P., \& Khan, K. (2011b). Kernel elastic properties and sedimentation: Influence of high and low molecular weight glutenin allelic composition. Cereal Chemistry, 88(1), 41-44. http://dx.doi.org/10.1094/CCHEM-10-09-0142

Gaines, C. S., Finney, P. L., \& Andrews, L. C. (1997). Influence of kernel size and shriveling on soft wheat milling and baking quality. Cereal Chemistry, 74(6), 700-704. http://dx.doi.org/10.1094/CCHEM.1997.74.6.700

Hrušková, M., \& Šmejd, P. (2003). Wheat flour dough alveograph characteristics predicted by NIRsystems 6500. Czech Journal of Food Science, 21(1), 28-33.http://www.cazv.cz/2003/CJFS1_03/4-Hruskova.pdf

Lyford, C. P., Kidd, W., Rayas-Duarte, P., \& Deyoe, C. (2005). Prediction of flour extraction rate in hard red winter wheat using the Single Kernel Characterization. Journal of Food Quality, 28(3), 279-288. http://dx.doi.org/10.1111/j.1745-4557.2005.00036.x

Martin, C.R., Rousser, R., \& Brabec, D.L. (1993). Development of a single kernel characterization system. Transactions of the ASAE, 36, 1399-1404. http://ddr.nal.usda.gov/bitstream/10113/42729/1/IND20387524.pdf

Miralbés, C. (2004). Quality control in the milling industry using near infrared transmittance spectroscopy. Food Chemistry. 88(4), 621-628. http://dx.doi.org/10.1016/j.foodchem.2004.05.004.

Ohm, J. B., Chung, O. K., \& Deyoe, C. W. (1998). Single-kernel characteristics of hard winter wheats in relation to milling and baking quality. Cereal Chemistry. 75(1), 156-161. http://dx.doi.org/10.1094/CCHEM.1998.75.1.156.

Osborne, B. G., Kotwal, Z., Blakeney, A. B., O'Brien, L., Shah, S., \& Fearn, T. (1997). Application of the single-kernel characterization system to wheat receiving testing and quality prediction. Cereal Chemistry, 74(4), 467-470. http://dx.doi.org/10.1094/CCHEM.1997.74.4.467

Osborne, B. G., Jackson, R., \& Delwiche, S. R. (2001). Rapid prediction of wheat endosperm compressive strength properties using the Single-Kernel Characterization System. Cereal Chemistry, 78(2), 142-143. http://dx.doi.org/10.1094/CCHEM.2001.78.2.142

Osborne, B. G., Henry, R. J., \& Southan, M. D. (2007). Assessment of commercial milling potential of hard wheat by measurement of the rheological properties of whole grain. Journal of Cereal Science, 45(2), 122-127. http://www.sciencedirect.com/science/article/B6WHK-4M2WP2K-1/2/c42dd633941e7c187521eb065189d62a

Xu, J., Bietz, J. A., Felker, F. C., Carriere, C. J., \& Wirtz, D. (2001). Rheological properties of vital wheat gluten suspensions. Cereal Chemistry, 78(2), 181-185. http://dx.doi.org/10.1094/CCHEM.2001.78.2.181

Yoon, B.-S., Brorsen, B. W., \& Lyford, C. P. (2002). Value of increasing kernel uniformity. Journal of Agricultural and Resource Economics, 27(2), 481-494. Retrieved April 26, 2011, from ABI/INFORM Global. (Document ID: 290040251). http://purl.umn.edu/31132 
Table 1. Descriptive Statistics of Wheat and Physical (Rheological) Dough Tests Data

\begin{tabular}{|l|l|l|l|l|l|l|l|l|l|l|l|l|}
\hline \multirow{2}{*}{ Variable } & \multicolumn{4}{|c|}{1998} & \multicolumn{3}{c|}{1999} & \multicolumn{3}{c|}{2000} & \multicolumn{3}{c|}{2001} \\
\cline { 2 - 15 } & Obs $^{\mathrm{a}}$ & Mean & SD $^{\mathrm{b}}$ & Obs & Mean & SD & Obs & Mean & SD & Obs & Mean & SD \\
\hline Test weight & 116 & 61.15 & 2.12 & 88 & 59.92 & 2.02 & 130 & 59.33 & 1.87 & 115 & 60.42 & 1.67 \\
\hline Wheat protein & 116 & 11.72 & 1.28 & 88 & 10.81 & 1.33 & 130 & 11.19 & 0.97 & 115 & 11.65 & 0.78 \\
\hline Kernel hardness & 116 & 78.04 & 11.95 & 88 & 72.88 & 7.68 & 130 & 79.23 & 9.07 & 115 & 77.91 & 5.62 \\
\hline Hardness SD & 116 & 16.13 & 2.87 & 88 & 17.91 & 1.78 & 130 & 18.76 & 1.59 & 115 & 17.96 & 1.85 \\
\hline Kernel diameter $^{116}$ & 2.19 & 0.17 & 88 & 2.26 & 0.17 & 130 & 2.24 & 0.12 & 115 & 2.3 & 0.1 \\
\hline Diameter SD $^{116}$ & 0.45 & 0.06 & 88 & 0.45 & 0.05 & 130 & 0.44 & 0.04 & 115 & 0.44 & 0.04 \\
\hline Peak time $^{\mathrm{c}}$ & 116 & 6.17 & 2.29 & 88 & 6.81 & 2.42 & 130 & 5.69 & 3.95 & 115 & 5.48 & 1.45 \\
\hline Stability $^{\mathrm{c}}$ & 116 & 6.91 & 3.47 & 88 & 10.71 & 3.35 & 130 & 12.13 & 5.41 & 115 & 8.33 & 2.71 \\
\hline Absorption $^{\mathrm{c}}$ & 116 & 62.39 & 3.75 & 88 & 61.14 & 2.98 & 130 & 60.65 & 2.02 & 115 & 61.66 & 2.03 \\
\hline
\end{tabular}

${ }^{\mathrm{a}} \mathrm{Obs}=$ number of observations.

${ }^{\mathrm{b}} \mathrm{SD}=$ standard deviation.

${ }^{c}$ Physical (rheological) dough test used for flour quality from a Farinograph; peak time, stability and absorption = optimum water absorption.

Table 2. Estimated Mixed Models of Wheat Flour Quality for Crop Years 1998, 1999, 2000, and 2001

\begin{tabular}{|c|c|c|c|c|c|c|}
\hline \multirow[t]{2}{*}{ Independent Variable } & \multicolumn{2}{|c|}{ Absorption $^{\mathrm{a}}$} & \multicolumn{2}{|c|}{ Peak Time $^{\mathrm{a}}$} & \multicolumn{2}{|c|}{ Stability $^{\mathrm{a}}$} \\
\hline & Coefficient & t-Value & Coefficient & t-Value & Coefficient & t-Value \\
\hline Intercept & $38.27 *$ & 9.87 & $17.91 *$ & 3.39 & $58.16^{*}$ & 7.3 \\
\hline Test weight & 0.04 & 0.65 & $-0.18^{*}$ & -2.34 & $-0.46^{*}$ & -4.01 \\
\hline Wheat protein & $1.78^{*}$ & 19.71 & $0.73^{*}$ & 5.91 & $-0.7^{*}$ & -3.77 \\
\hline Hardness & $0.04 *$ & 3.24 & $-0.04 *$ & -2.49 & $-0.07 *$ & -3.16 \\
\hline Hardness SD ${ }^{b}$ & $-0.18 *$ & -4.07 & -0.07 & -1.07 & 0.05 & 0.55 \\
\hline Diameter & 0.11 & 0.16 & $-2.23 *$ & -2.4 & -2.26 & -1.62 \\
\hline Diameter SD & 2.46 & 1.24 & -0.92 & -0.34 & -7.86 & -1.94 \\
\hline \multicolumn{7}{|c|}{ Covariance Parameter } \\
\hline Random effect $\left(v^{2}\right)$ & 0.27 & & 0.41 & & 2.94 & \\
\hline Error variance $\left(\sigma^{2}\right)$ & 3.37 & & 6.31 & & 14.08 & \\
\hline \multicolumn{7}{|c|}{ Null Model Likelihood Ratio Test } \\
\hline Chi-square & 14.03 & & 10.64 & & 40.55 & \\
\hline Pr $>$ Chi-square & 0.0002 & & $<0.0011$ & & $<0.0001$ & \\
\hline
\end{tabular}

${ }^{a}$ Physical (rheological) dough test used for flour quality using a Farinograph; optimum water absorption, peak time, and stability.

${ }^{\mathrm{b}} \mathrm{SD}=$ standard deviation.

* Denotes significance at the 5\% level.

Table 3. Estimated Models of Flour Quality by Crop Year

\begin{tabular}{|l|c|c|c|c|c|c|}
\hline \multirow{2}{*}{ Independent Variable } & \multicolumn{2}{|c|}{ Absorption $^{\mathrm{a}}$} & \multicolumn{2}{c|}{ Peak Time $^{\mathrm{a}}$} & \multicolumn{2}{c|}{ Stability $^{\mathrm{a}}$} \\
\cline { 2 - 7 } & Coefficient & $\mathrm{t}-$ Value & Coefficient & $\mathrm{t}$-Value & Coefficient $^{\text {t-Value }}$ \\
\hline \multicolumn{7}{|c|}{1998} \\
\hline Intercept & $58.56^{*}$ & 6.27 & $20.16^{*}$ & 2.45 & $56.04^{*}$ & 4.92 \\
\hline Test weight & $-0.28^{*}$ & -2.1 & -0.22 & -1.88 & $-0.49^{*}$ & -3.01 \\
\hline Wheat protein & $1.95^{*}$ & 9.04 & 0.09 & 0.5 & $-1.27^{*}$ & -4.84 \\
\hline Hardness & 0.02 & 0.53 & 0.02 & 0.83 & -0.001 & -0.03 \\
\hline Hardness SD & -0.16 & -1.31 & -0.07 & -0.62 & -0.05 & -0.37 \\
\hline Diameter & -0.21 & -0.13 & -1.33 & -0.94 & -3.14 & -1.61 \\
\hline Diameter SD & 0.29 & 0.07 & 1.93 & 0.49 & 8.21 & 1.5 \\
\hline R-Squared & 0.56 & $0.54^{\mathrm{b}}$ & 0.09 & $0.04^{\mathrm{b}}$ & 0.24 & $0.2^{\mathrm{b}}$ \\
\hline \multicolumn{7}{|c|}{1999} \\
\hline Intercept & $24.49^{*}$ & 4.78 & $22.46^{*}$ & 2.83 & $70.09^{*}$ & 5.81 \\
\hline Test weight & $0.17^{*}$ & 2.19 & $-0.28^{*}$ & -2.38 & $-0.55^{*}$ & -3.05 \\
\hline Wheat protein & $1.98^{*}$ & 16.65 & $0.83^{*}$ & 4.5 & $-1.17^{*}$ & -4.18 \\
\hline Hardness & $0.06^{*}$ & 3.22 & -0.03 & -1.07 & -0.06 & -1.27 \\
\hline Hardness SD & -0.01 & -0.12 & -0.07 & -0.5 & -0.09 & -0.43 \\
\hline Diameter & 0.6 & 0.64 & -2.28 & -1.57 & -1.52 & -0.69 \\
\hline Diameter SD & -1.39 & -0.48 & 2.22 & 0.5 & -10 & -1.47 \\
\hline R-Squared & 0.84 & $0.83^{\mathrm{b}}$ & 0.43 & $0.38^{\mathrm{b}}$ & 0.3 & $0.25^{\mathrm{b}}$ \\
\hline
\end{tabular}




\begin{tabular}{|l|c|c|c|c|c|c|}
\hline \multicolumn{7}{|c|}{2000} \\
\hline Intercept & $33.4^{*}$ & 5.12 & 16.58 & 1.18 & $49.79^{*}$ & 2.27 \\
\hline Test weight & 0.18 & 1.84 & 0.16 & 0.73 & 0.22 & 0.67 \\
\hline Wheat protein & $1.22^{*}$ & 8.13 & $2.11^{*}$ & 6.55 & 0.94 & 1.88 \\
\hline Hardness & $0.05^{*}$ & 2.52 & $-0.2^{*}$ & -4.71 & $-0.32^{*}$ & -4.86 \\
\hline Hardness SD & -0.08 & -0.89 & $-0.42^{*}$ & -2.27 & -0.25 & -0.86 \\
\hline Diameter & -0.99 & -0.82 & $-6.55^{*}$ & -2.52 & -7.26 & -1.79 \\
\hline Diameter SD & 5.83 & 1.55 & -11.8 & -1.46 & $-33.38^{*}$ & -2.65 \\
\hline R-Squared & 0.54 & $0.52^{\mathrm{b}}$ & 0.44 & $0.41^{\mathrm{b}}$ & 0.27 & $0.24^{\mathrm{b}}$ \\
\hline \multicolumn{7}{|c|}{2001} \\
\hline Intercept & 5.6 & 0.66 & 3.3 & 0.37 & $45.21^{*}$ & 2.72 \\
\hline Test weight & $0.25^{*}$ & 1.99 & 0.19 & 1.42 & -0.18 & -0.75 \\
\hline Wheat protein & $1.66^{*}$ & 9.73 & 0.37 & 2.04 & 0.02 & 0.07 \\
\hline Hardness & $0.08^{*}$ & 3.04 & -0.03 & -1.18 & -0.06 & -1.23 \\
\hline Hardness SD & -0.11 & -1.4 & 0.07 & 0.84 & 0.09 & 0.58 \\
\hline Diameter & $4.84^{*}$ & 3.27 & -2.96 & -1.91 & -5.64 & -1.94 \\
\hline Diameter SD & $14.88^{*}$ & 4.29 & $11.89^{*}$ & -3.26 & $-22.45^{*}$ & -3.29 \\
\hline R-Squared & 0.62 & $0.59^{\mathrm{b}}$ & 0.17 & $0.12^{\mathrm{b}}$ & 0.16 & $0.12^{\mathrm{b}}$ \\
\hline
\end{tabular}

aphysical (rheological) dough test for flour quality using a Farinograph; optimum water absorption, peak time, and stability.

${ }^{\mathrm{b}}$ Denotes adjusted R-Squared.

* Denotes significance at the $5 \%$ level.

Table 4. Elasticity between Wheat Kernel Properties and Flour Quality by Crop Year

\begin{tabular}{|l|c|c|c|}
\hline Wheat Property & Absorption $^{\mathrm{a}}$ & Peak Time $^{\mathrm{a}}$ & Stability $^{\mathrm{a}}$ \\
\hline Test weight & -0.274 & -2.180 & -4.336 \\
\hline Wheat protein & 0.366 & 0.171 & -2.154 \\
\hline Hardness & 0.025 & 0.253 & -0.011 \\
\hline Hardness SD & -0.041 & -0.183 & -0.117 \\
\hline Diameter & -0.007 & -0.472 & -0.995 \\
\hline Diameter SD & 0.002 & 0.141 & 0.535 \\
\hline \multicolumn{4}{|c|}{1999} \\
\hline Test weight & 0.167 & -2.464 & -3.077 \\
\hline Wheat protein & 0.350 & 1.318 & -1.181 \\
\hline Hardness & 0.072 & -0.321 & -0.408 \\
\hline Hardness SD & -0.003 & -0.184 & -0.151 \\
\hline Diameter & 0.022 & -0.757 & -0.321 \\
\hline Diameter SD & -0.010 & 0.147 & -0.420 \\
\hline \multicolumn{4}{|c|}{2000} \\
\hline Test weight & 0.176 & 1.668 & 1.076 \\
\hline Wheat protein & 0.225 & 4.150 & 0.867 \\
\hline Hardness & 0.065 & -0.278 & -2.090 \\
\hline Hardness SD & -0.025 & -1.385 & -0.387 \\
\hline Diameter & -0.037 & -2.579 & -1.341 \\
\hline Diameter SD & 0.042 & -0.912 & -1.211 \\
\hline \multicolumn{4}{|c|}{2001} \\
\hline Test weight & 0.245 & 2.095 & -1.306 \\
\hline Wheat protein & 0.314 & 0.787 & 0.028 \\
\hline Hardness & 0.101 & -0.427 & -0.561 \\
\hline Hardness SD & -0.032 & 0.229 & 0.194 \\
\hline Diameter & 0.181 & -1.242 & -1.557 \\
\hline Diameter SD & 0.106 & 0.955 & -1.186 \\
\hline
\end{tabular}

Note: Elasticities show the percentage change in the dependent variable with a percentage change in the independent variable. For example, the first elasticity of -0.274 means that if test weight goes up $1 \%$, absorption decreases $0.274 \%$.

${ }^{a}$ Physical (rheological) dough test for flour quality using a Farinograph; optimum water absorption, peak time, and stability.

${ }^{\mathrm{c}} \mathrm{SD}=$ standard deviation. 